\title{
Dissimilar metal joining of stainless steel and titanium using copper as transition metal
}

\author{
Gonçalo Pardal $^{1} \cdot$ Supriyo Ganguly ${ }^{1} \cdot$ Stewart Williams $^{1} \cdot$ Jay Vaja $^{2}$
}

Received: 27 September 2015 / Accepted: 12 November 2015 /Published online: 5 January 2016

(C) The Author(s) 2016. This article is published with open access at Springerlink.com

\begin{abstract}
Joining of stainless steel and titanium dissimilar metal combination has a specific interest in the nuclear industry. Due to the metallurgical incompatibility, it has been very difficult to produce reliable joints between these metals due to the formation of $\mathrm{FeTi}$ and $\mathrm{Fe}_{2} \mathrm{Ti}$ types of intermetallic compounds. The metallurgical incompatibility between both materials is enhanced by the time-temperature profile of the welding process used. Brittle intermetallics (IMCs) are formed during FeTi welding ( $\mathrm{FeTi}$ and $\mathrm{Fe}_{2} \mathrm{Ti}$ ). The present study uses the low thermal heat input process cold metal transfer (CMT), when compared with conventional GMAW, to deposit a copper $(\mathrm{Cu})$ bead between $\mathrm{Ti}$ and stainless steel. $\mathrm{Cu}$ is compatible with $\mathrm{Fe}$, and it has a lower melting point than the two base materials. The welds were produced between AMS 4911L (Ti-6Al-4V) and AISI 316L stainless steel using a CuSi-3 welding wire. The joints produced revealed two IM layers located near the parent metals/weld interfaces. The hardness of these layers is higher than the remainder of the weld bead. Tensile tests were carried out with a maximum strength of $200 \mathrm{MPa}$, but the interfacial failure could not be avoided. Ti atomic migration was observed during experimental trials; however, the IMC formed are less brittle than FeTi, inducing higher mechanical properties.
\end{abstract}

Gonçalo Pardal

g.n.pardalrodrigues@cranfield.ac.uk

Supriyo Ganguly

s.ganguly@cranfield.ac.uk

Stewart Williams

s.williams@cranfield.ac.uk

Jay Vaja

Jay.Vaja@awe.co.uk

1 Cranfield University-Welding Engineering and Laser Processing Centre, Bedford MK43 0Al, UK

2 AWE-Aldermaston Reading, Berkshire RG7 4PR, UK
Keywords Titanium - Stainless steel · Intermetallic · Dissimilar welding

\section{Introduction}

The main challenge when joining dissimilar metals is the metallurgical incompatibility of the metals used. This is applicable to the dissimilar joint of titanium (Ti) and stainless steel $(\mathrm{Fe})$. This incompatibility is reflected by the formation of intermetallic (IMC) phases formed during the welding of these materials. Binary phase diagrams show the different IMC phases formed during equilibrium conditions for a particular combination of materials. In Fig. 1, the phase diagram between $\mathrm{Fe}$ and $\mathrm{Ti}[1]$ is shown.

The Fe-Ti binary phase diagram depicts also the absence of solid solubility between $\mathrm{Fe}$ and Ti.

IMC formation is also dependent on the time-temperature profile that both metals are subjected. As the IMC formation is dependant of diffusion and reaction between the parent metals, an increase in the time-temperature cycles increases the mobility of the metals and, consequently, the formation of different IMC phases. To avoid the formation of brittle IMCs, there are two different routes or a combination of the two that can be followed:

- Welding process control (low heat input).

- Weld metal engineering (use of other metals to change the weld pool composition).

\subsection{Welding process control}

This route uses physical principles to deter the IMC formation. As the IMC formation is mainly controlled by diffusion and 
Fig. 1 Fe-Ti binary phase diagram

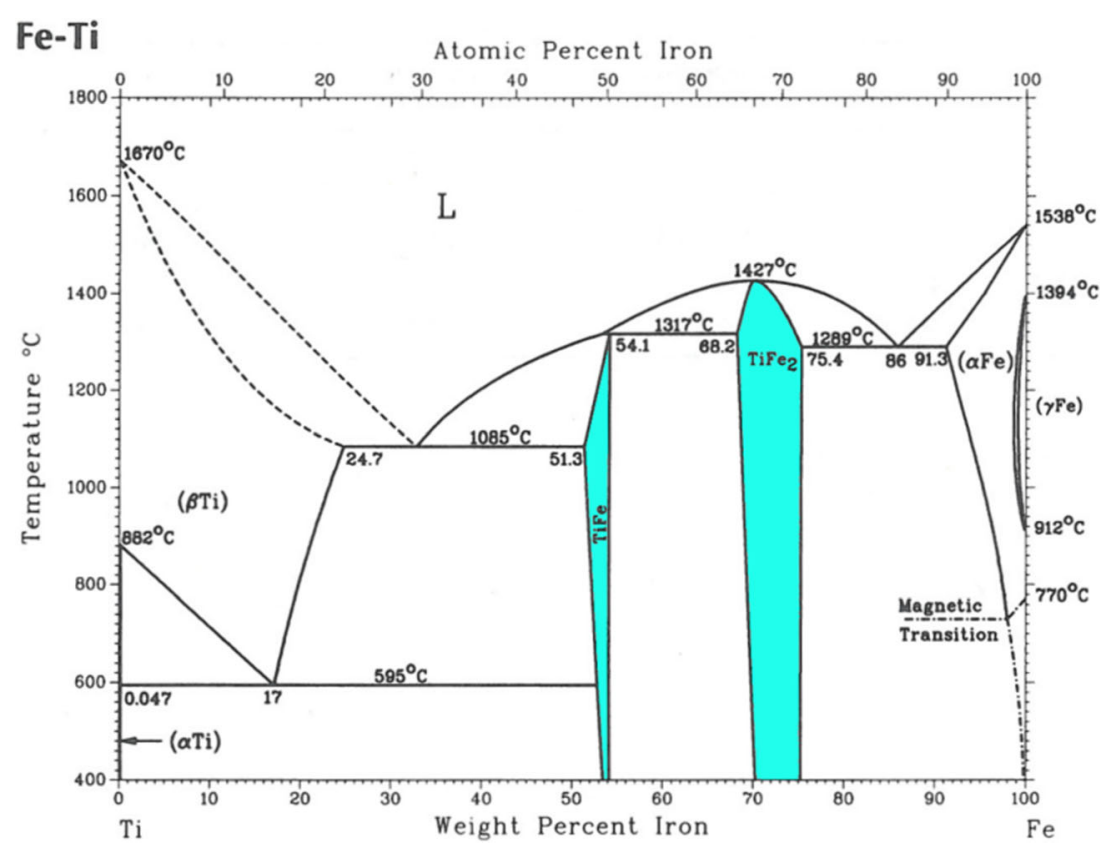

reaction processes if the heat input and the interaction time are lowered, they will induce lower IMCs. Several studies were made to join stainless steel and Ti using low thermal input processes as diffusion bonding [2,3] and friction stir welding [4]. In the first study, D. Poddar used diffusion bonding to join commercially pure $(\mathrm{CP})$ titanium to precipitation hardening stainless steel. D. Poddar verified that a temperature of $950{ }^{\circ} \mathrm{C}$ with a holding time of $3600 \mathrm{~s}$ and with a loading of 4 to $6 \mathrm{E}-3 \mathrm{MPa}$ could achieve the best joint conditions. This joint had a reaction layer of $79.9 \mu \mathrm{m}$ but had a tensile strength of $344.3 \mathrm{MPa}$ and an elongation of $12.8 \%$. S. Kundu et al. also used diffusion bonding to join $\mathrm{CP}$ titanium and microduplex stainless steel obtaining also a reaction layer and joint properties of $306 \mathrm{MPa}$ of tensile strength with ductility of $6.9 \%$. M. Fazel-Najafabadi et al. used friction stir welding to lap weld CP Ti with 304 stainless steel using a double shoulder tool. The presence of Ti-Fe IMC compounds was detected, but the strength of the sample was attributed to the bimetallic vortices that contributed to a mechanical interlock. The samples obtained had maximum shear strength of $119 \mathrm{MPa}$. Explosive welding was also used to joint titanium and stainless steel; these joints were defect free and no IMCs were detected at the joint interface [5], but the flexibility of explosion welding is very low when compared with the fusion welding processes. To allow more flexibility to the welding process, laser in key-hole mode was also studied [6]; however, even with high cooling rates obtained by this process, it was not possible to make any sound joint.

\subsection{Weld metal engineering}

The second route is to control the reaction between the two alloys by adding a third metal that inhibits IMC formation or that modifies the IMC composition suitably to make it tougher. Silver and silver alloys have been studied due to its low melting point and high compatibility towards $\mathrm{Fe}$. In [7], J. Lee et al. used an $\mathrm{Ag}$ interlayer of 20 and $40 \mu \mathrm{m}$ to braze titanium and stainless steel. The brazing material remained in the centre of the weld and prevented the formation of the brittle $\mathrm{Fe}-\mathrm{Ti}$ IMCs and substitute them to AgTi IMCs which improved the joint strength considerably. Other metal researched on joining of $\mathrm{Ti}$ and stainless steel is $\mathrm{Ni}$, the melting temperature is higher than $\mathrm{Ag}$, but it is also very compatible with $\mathrm{Fe}$. $\mathrm{R}$ Shiue et al. [8] used a commercial silver alloy (BAg-8) to braze Ti-6Al-4V to $17-4 \mathrm{PH}$ stainless steel coated with a $10 \mu \mathrm{m} \mathrm{Ni}$ barrier layer. Using the $\mathrm{Ni} \mathrm{Ag}$ combination, they managed to avoid the formation of $\mathrm{Fe}-\mathrm{Ti}$ IMCs. $\mathrm{Cu}$

Table 1 Parent material atomic composition (\%wt)

\begin{tabular}{lllllllllllllllllllllll}
\hline Material & $\mathrm{C}$ & $\mathrm{Si}$ & $\mathrm{Mn}$ & $\mathrm{P}$ & $\mathrm{S}$ & $\mathrm{Cr}$ & $\mathrm{Ni}$ & $\mathrm{Mo}$ & $\mathrm{N}$ & $\mathrm{Fe}$ & $\mathrm{Pb}$ & $\mathrm{Al}$ & & $\mathrm{Cu}$ & $\mathrm{V}$ & $\mathrm{Y}$ & $\mathrm{H}$ & $\mathrm{O}$ \\
\hline Stainless steel 316L & 0.020 & 0.45 & 1.73 & 0.032 & 0.01 & 17.2 & 10.0 & 2.07 & 0.054 & $\mathrm{Bal}$ & - & - & & - & - & - & - \\
AMS 4911L & 0.08 & - & - & - & - & - & - & - & 0.5 & 0.3 & - & 5.5 & -6.75 & - & $3.5-4.5$ & 0.005 & 0.0125 & 0.2 \\
CuSi-3 & - & 3.0 & 1.1 & - & - & - & - & - & - & 0.1 & 0.01 & 0.03 & & $\mathrm{Bal}$ & - & - & - & - \\
\hline
\end{tabular}


Fig. 2 Schematics from the welding-brazing technique

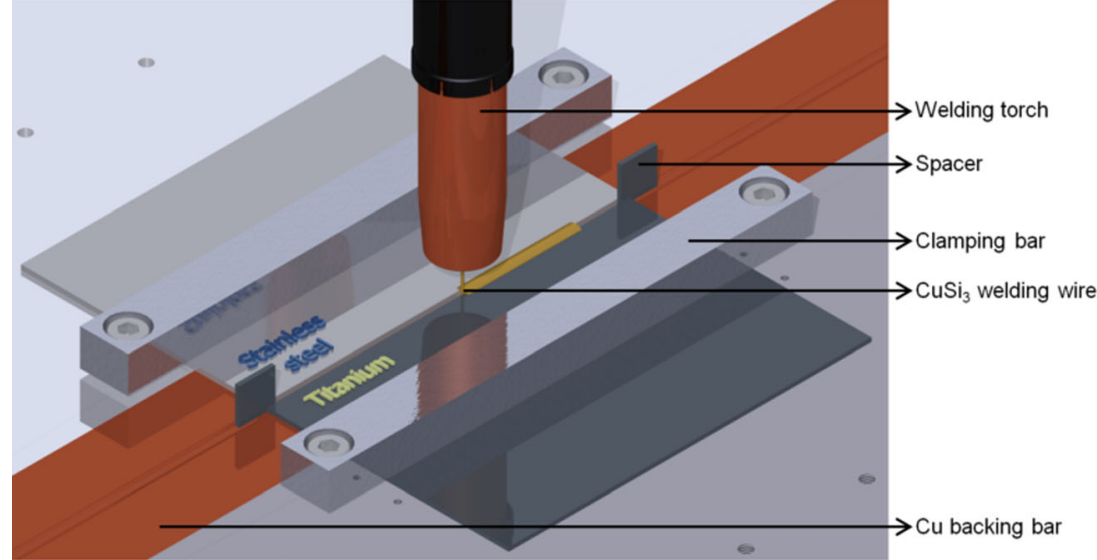

was also studied as a barrier for the IMC formation. T. Wang et al. [9] investigated electron beam welding with a thick interlayer of $1 \mathrm{~mm}$, but the formation of IMC could not be avoided as dispersive distribution of $\mathrm{TiFe}_{2} \mathrm{IMCs}$, and $\mathrm{Ti}-\mathrm{Cu}$ and $\mathrm{Ti}-\mathrm{Cu}-\mathrm{Fe}$ IM compounds were observed. Electron beam welding and pulsed laser welding were investigated by I. Tomashchuck et al. [10] using a $0.5 \mathrm{~mm}$ pure $\mathrm{Cu}$ interlayer. The tensile strength of the joints was limited by the different $\mathrm{Ti}-\mathrm{Cu}$ IMC present. S. Kundu et al. [11] used diffusion bonding and a $300 \mu \mathrm{m} \mathrm{Cu}$ interlayer obtaining a maximum tensile strength of $318 \mathrm{MPa}$ and a ductility of $8.5 \%$

The present investigation reported a combination of these two main strategies to improve the mechanical properties of $\mathrm{Ti}$ to stainless steel welding. $\mathrm{Cu}$ was selected as a transition metal due to its lower melting temperature vs mechanical properties relationship when compared to other possible transition metals like $\mathrm{Ag}$ and $\mathrm{Ni}$. $\mathrm{Cu}$ is compatible with $\mathrm{Fe}$, and the IMC phases produced with $\mathrm{Ti}$ are tougher than the $\mathrm{Fe}-\mathrm{Ti}$ IMC. It also used a low heat input cold metal transfer (CMT) welding process when compared with conventional GMAW welding. CMT relies in wire control and surface tension to detach the molten metal and deposit it. This reduces the time-

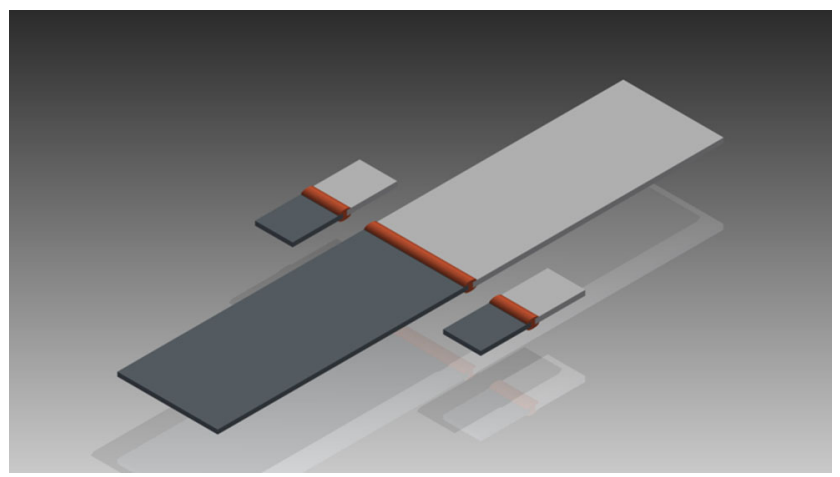

Fig. 3 Sample preparation for metallographic analysis (two) and the sample for mechanical tests temperature cycle, decreasing diffusion and IMC formation. A copper backing bar was used to quickly extract the heat generated during the welding process. CMT was chosen not only for its low heat input, but also by its flexibility (does not need a furnace, can be used for different types of joints, can adapt to several joint designs and or paths, etc.) when compared with some of the joining processes mentioned before (infrared brazing, explosion welding, etc.)

\section{Experimental procedure and materials}

Titanium AMS4911L plates of dimensions $150(L) \times 100$ $(W) \times 1.7 \mathrm{~mm}(T)$ were joined with $316 \mathrm{~L}$ stainless steel of identical length and width but with $2 \mathrm{~mm}$ in thickness. The chemical composition of the alloys and the filler wires used in the experiments is given in Table 1.

Each plate was manually ground and linished prior to the welding-brazing process with particular attention to the surfaces that form the gap brazed by the $\mathrm{CuSi}-3$ welding wire (vertical faces). The plates were joined in butt welding configuration with $1.7 \mathrm{~mm}$ gap. This gap was obtained by controlled experimentation in an attempt

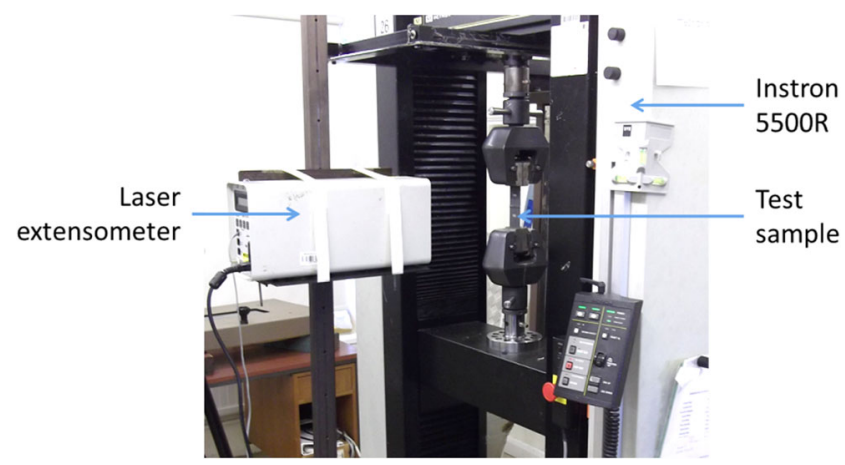

Fig. 4 Tensile test setup used for CMT $\mathrm{Cu}$ welded samples 
to empirically optimise the welding process. A narrower gap would result in lack of fusion type defect near the root by improper wetting by the copper alloy while larger gap would cause underfilling. A $1 \mathrm{~mm}$ diameter $\mathrm{CuSi}-3$ welding wire was deposited between the $\mathrm{Ti}$ and stainless steel plates using CMT welding process (Fig. 2).

After the welding process, three different specimens were produced as shown in Fig. 3, one for mechanical tests and two for metallographic analysis.

Metallographic specimens were prepared by mounting them on conductive resin for electron microscopy, ground using silicon carbide paper and polished using diamond paste and colloidal silicon suspension mixed with oxalic acid. They were analysed by optical microscopy, scanning electron microscopy and electron-dispersive spectroscopy (SEM/EDS). Hardness mapping of the specimen was carried out by a Zwick microhardness machine, with the following parameters: HV0.1/10 [12]. Each sample extracted to mechanical tests was tested using the $100 \mathrm{kN}$ INSTRON 5500R tensile test machine. The tensile test was performed at a constant speed of $1 \mathrm{~mm}$ per second; the load and displacement were acquired by a National Instruments system attached to a laser extensometer (Fig. 4). The gauge length used during the experiments was $50 \mathrm{~mm}$.

\section{Welding parameters}

The experiments were carried out using constant welding parameters (travel speed $-0.5 \mathrm{~m} / \mathrm{min}$, contact tip to work piece distance - $13.5 \mathrm{~mm}$ and CMT mode - 1183), except the wire

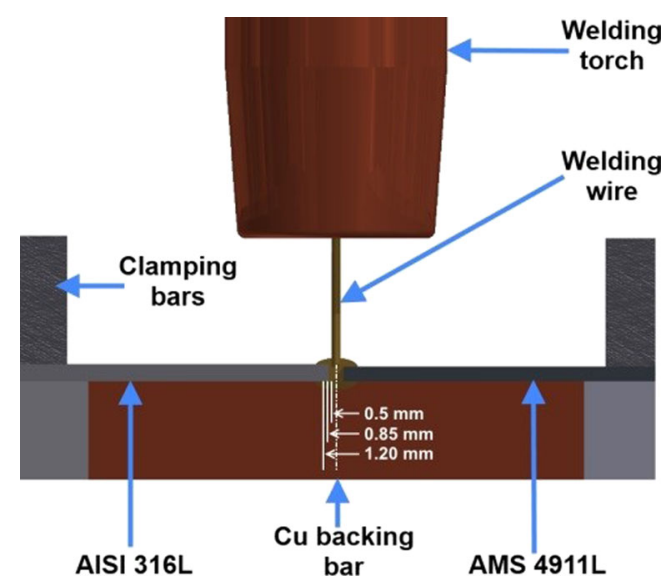

Fig. 5 Welding wire positioning during the welding-brazing experiments

feed speed that was varied as shown in Table 2. As CMT is a synergic process changing the wire feed speed, it would change the current and voltage, translating to a heat input variation that is shown by the following expression:

$H I=\eta \frac{V . I}{T S}$

where $\mathrm{HI}$ is the heat input, $V$ is the voltage, $I$ is the intensity, TS is the travel speed and $\eta$ is the welding process efficiency that for a MIG process has CMT is stipulated as 0.85 [13].

The welding wire was positioned towards the stainless steel plate to enhance the melting of stainless steel and avoid Ti melting. This will prevent the diffusion of Ti into the weld pool and avoid the formation of $\mathrm{Fe}-\mathrm{Ti}$ intermetallics. Figure 5 depicts the experimental setup and the different positioning of the welding wire in relation to the central line of the gap between the parent metals.

Table 2 CMT welding-brazing parameters for the welding-brazing experiments

\begin{tabular}{lllll}
\hline Sample & Offset $(\mathrm{mm})$ & Wire feed speed $(\mathrm{m} / \mathrm{min})$ & Heat input $(\mathrm{J} / \mathrm{mm})$ & Fracture location \\
\hline CMT 1 & 0.50 & 5.00 & 110.76 & Stainless \\
CMT 2 & 0.50 & 6.00 & 118.40 & Stainless \\
CMT 3 & 0.50 & 7.00 & 140.75 & Stainless \\
CMT 4 & 0.50 & 8.00 & 157.67 & Stainless \\
CMT 5 & 0.50 & 9.00 & 154.99 & Ti \\
CMT 6 & 0.85 & 5.00 & 101.83 & Stainless \\
CMT 7 & 0.85 & 6.00 & 116.51 & Stainless \\
CMT 8 & 7.00 & 135.01 & Stainless \\
CMT 9 & 0.85 & 8.00 & 149.91 & Stainless \\
CMT 10 & 0.85 & 9.00 & 171.44 & Ti \\
CMT 11 11.00 & Stainless \\
CMT 12 & 0.85 & 5.00 & 115.47 & Stainless \\
CMT 13 & 1.20 & 6.00 & 138.44 & Stainless \\
CMT 14 & 1.20 & 7.00 & 152.99 & Cu bead \\
CMT 15 & 1.20 & 8.00 & 152.59 & Ti \\
\hline
\end{tabular}




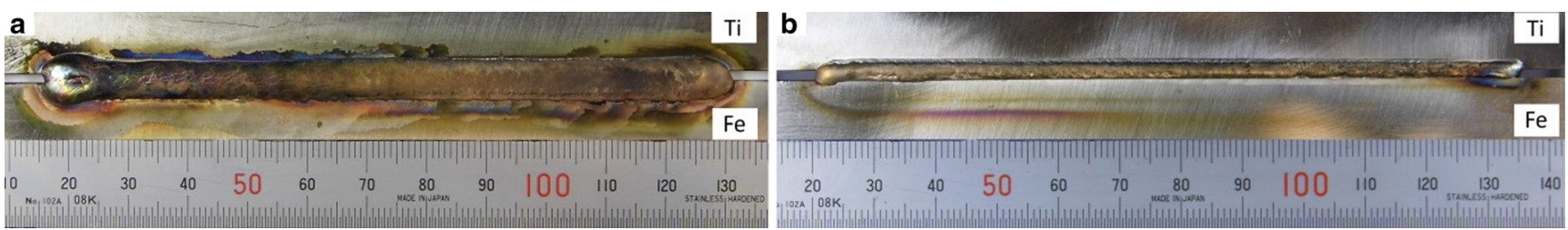

Fig. 6 Weld bead stability and oxidation from sample CMT 11: a top surface and b weld root

Table 2 contains the experimental points used during these experimental trials.

The remainder constant parameters not shown in Table 2 are as follows:

- Contact tip to work distance (CTWD)-13 mm

- Shielding gas flows
- CMT torch-22 1/min
$\circ$ Back shielding-2 1/min
○ Trailing shield $-62.5 \mathrm{l} / \mathrm{min}$

- Torch angle $0^{\circ}$ perpendicular to the parent metals

\section{Results}

\subsection{Weld bead geometry}

Similar weld bead geometry was obtained, as shown in Fig. 6, from all the different experimental trials listed in Table 2.
The top surface (Fig. 6a) showed traces of oxidation even though a trailing shield was used; however, the weld root was successfully shielded with no apparent sign of oxidation (Fig. 6b).

After macroscopic analysis, it is possible to verify that the weld bead geometry is very similar for all of the welded samples. The welding wire positioning does not influence the weld bead geometry (Fig. 7 (I, II and III)). However, the geometry is slightly different when the heat input is increased (Fig. 7a-c).

Samples with low heat input, i.e. with lower wire feed speeds as shown in Fig. 7a (I, II and III), do not wet correctly the stainless steel plate. A clear undercut can be seen at the $\mathrm{Fe}-\mathrm{Cu}$ interface; this is due to a low heat input and a fast solidification of the melt pool when in contact with the stainless steel plate. As the heat input is increased in samples in Fig. 7b, c, a better wetting of the stainless steel plate is achieved. However, the contribution of the parent metals in the $\mathrm{Cu}$ bead is more noticeable (higher melting of parent metals).

With the microscopic examination, it is also possible to identify three different areas in each joined sample: two different reaction layers between the parent metals
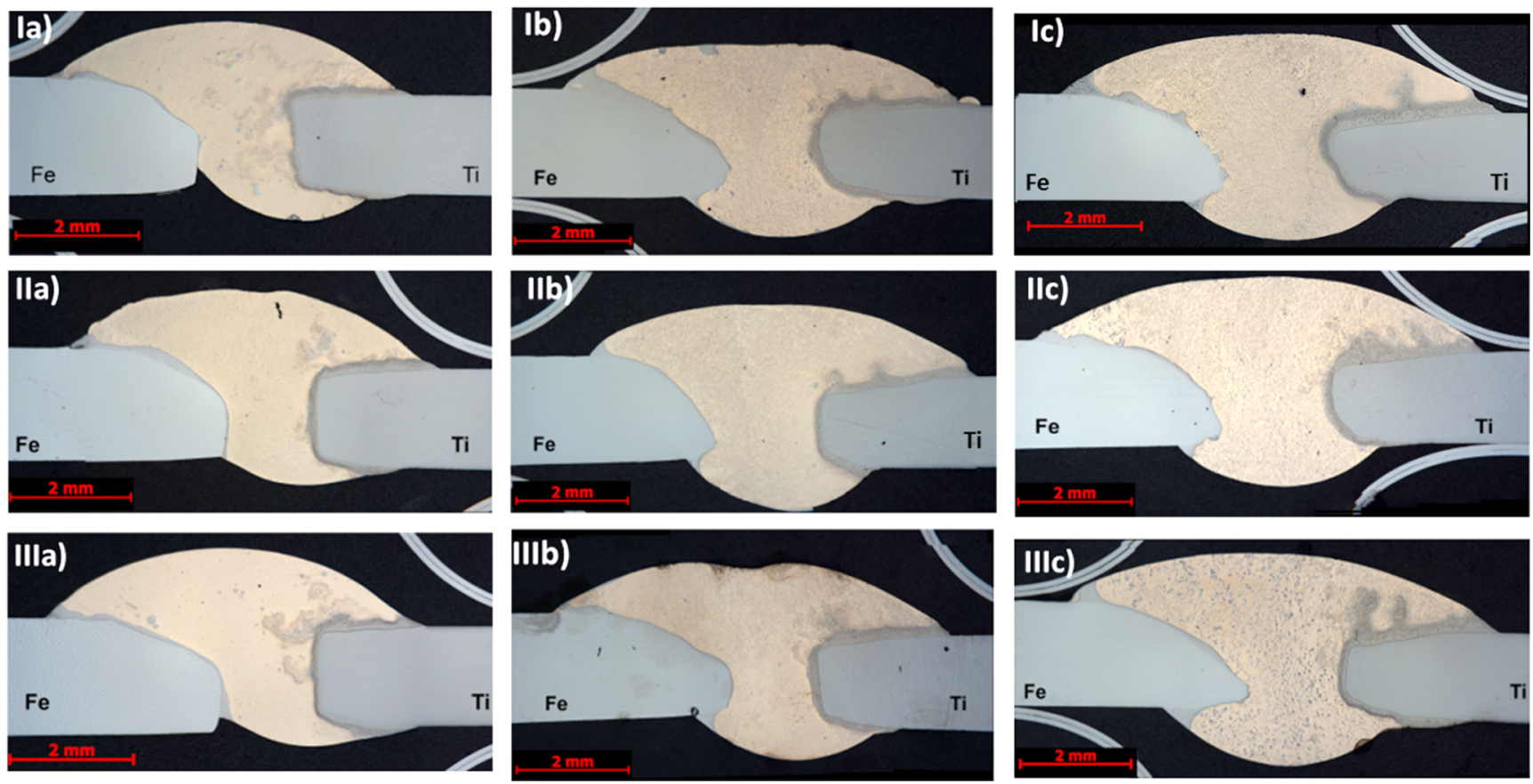

Fig. 7 Selected sample macrographs. $I-0.5 \mathrm{~mm}, I I-0.85 \mathrm{~mm}, I I I-1.20 \mathrm{~mm}, \mathbf{a}-\mathbf{c}$ increasing the wire feed speed 
a
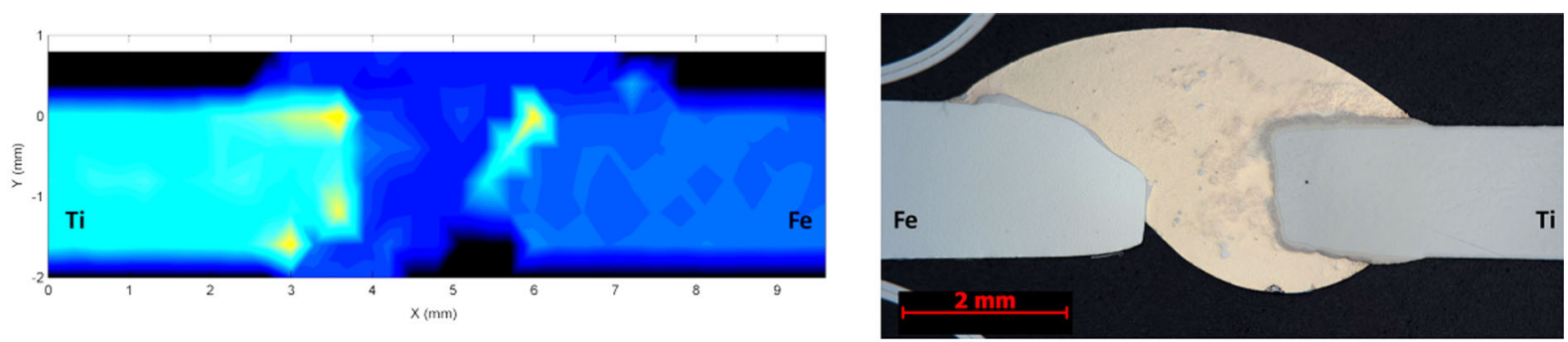

b
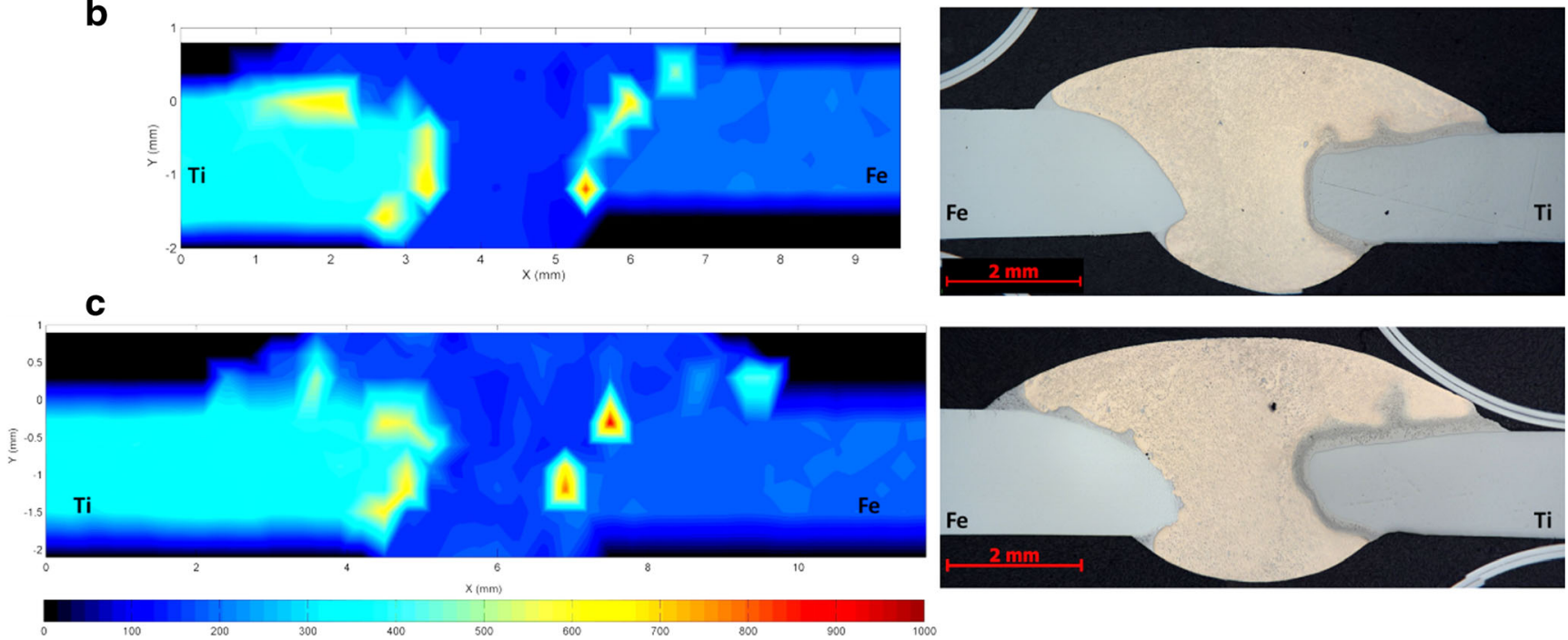

Fig. 8 Hardness mapping and corresponding optical macrographs for samples: a CMT 2, b CMT 4 and c CMT 5

and the $\mathrm{Cu}$ bead and also the $\mathrm{Cu}$ bead with several dispersed phases.

\subsection{Hardness evaluation}

As stated in Sect. 1, this metallic combination ( $\mathrm{Fe}-\mathrm{Cu}-\mathrm{Ti})$ can generate IMC phases, and so, to identify their location, microhardness testing was carried out.

Three samples were selected for these tests, CMT 2, 4 and 5 (Table 2). The three samples selected were made at the same welding wire positioning $(0.5 \mathrm{~mm}$ from the centre of the gap and towards the stainless steel) and have increasing heat inputs. CMT 2 and 4 have failed at the
$\mathrm{Fe}-\mathrm{Cu}$ interface whilst sample CMT 5 has failed at the $\mathrm{Cu}-\mathrm{Ti}$ interface.

Figure 8 shows the hardness mapping results for the three selected samples (Fig. 7a-c (I)).

All of the specimens tested showed similar hardness profiles with the bulk of the $\mathrm{Cu}$ deposited bead being the softer part of the joint and as expected; the higher hardness values are concentrated at the interfaces between the $\mathrm{Cu}$ bead and the stainless steel and Ti plates, at previously observed reaction layers.

Sample CMT 2 has the lower average hardness due to the lower heat input used in this weld. This lower heat input induces a lower melting of the parent metals, a

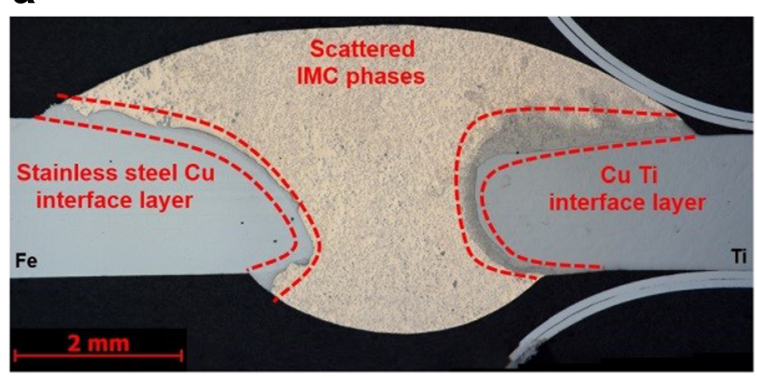

b

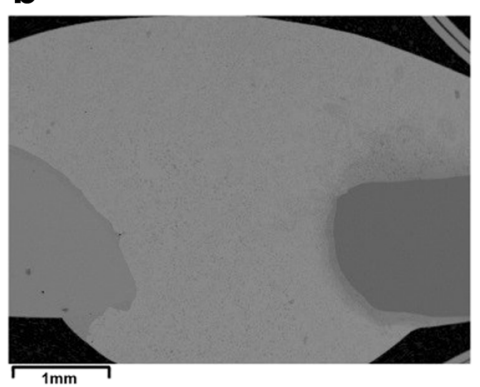

C

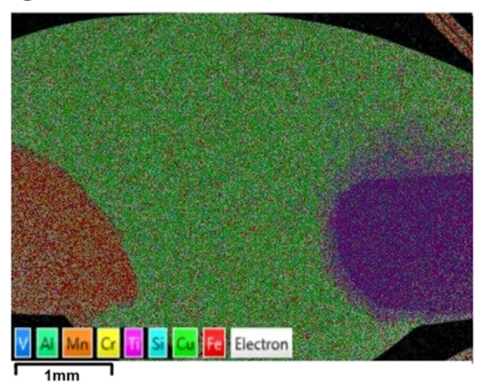

Fig. 9 a $\mathrm{Cu}$ deposited weld bead macrograph and distinctive areas. b Backscattered SEM image. $\mathbf{c}$ EDS mapping showing the main elements present on the sample 
Table 3 Elemental composition in weight percentage from the phases identified on the stainless steel-Cu interface layer

\begin{tabular}{lllllllll}
\hline & A & B & C & D & E & F & G & H \\
\hline $\mathrm{Si}$ & 0.39 & 1.54 & 3.95 & 5.59 & 0.87 & 8.87 & 10.14 & 5.71 \\
$\mathrm{Ti}$ & - & - & 0.82 & 0.57 & 0.12 & 6.29 & 14.47 & 0.69 \\
$\mathrm{~V}$ & - & - & - & - & - & - & - & 0.36 \\
$\mathrm{Cr}$ & 17.96 & 0.27 & 18.11 & 16.92 & 0.92 & 14.24 & 10.63 & 17.06 \\
$\mathrm{Mn}$ & - & 1.21 & - & - & 1.07 & 0 & 0 & 0 \\
$\mathrm{Fe}$ & 70.37 & 1.86 & 66.36 & 67.43 & 5.07 & 54.22 & 46.59 & 67.14 \\
$\mathrm{Ni}$ & 9.41 & - & 5.82 & 4.61 & - & 6.29 & 3.79 & 3.79 \\
$\mathrm{Cu}$ & - & 95.14 & 3.92 & 4.48 & 91.97 & 8.04 & 3.16 & 4.18 \\
$\mathrm{Mo}$ & 1.89 & - & 1.03 & 0.4 & - & 2.08 & 11.22 & 1.07 \\
\hline
\end{tabular}

reducing the diffusion/reaction between intervening $\mathrm{Fe}$, Ti and $\mathrm{Cu}$.

On the contrary, samples CMT 4 and 5 have higher average hardness particularly at the $\mathrm{Fe}-\mathrm{Cu}$ and $\mathrm{Ti}-\mathrm{Cu}$ interfaces. This can be justified by the higher heat input and, consequently, the increase in the melting of the parent metals that will originate higher interdiffusion. The higher hardness values for both these samples are located at the $\mathrm{Cu}-\mathrm{Fe}$ interface with values close to $1000 \mathrm{HV}$. However, the facture location of both of these samples is located in different parts of the sample. For CMT 4, the fracture location is at the $\mathrm{Fe}-\mathrm{Cu}$ interface that coincides with the location of the hardest IMC phases whilst, for sample CMT 5, the location is at the $\mathrm{Ti}-\mathrm{Cu}$ interface. This indicates not only that the IMC hardness is the major contributing factor for the failure of this joint, but also that the IMC volume plays a role in failure location. As the time-temperature profile increases with the increase of the heat input, the $\mathrm{Ti}-\mathrm{Cu}$ IMC layer volume increases,

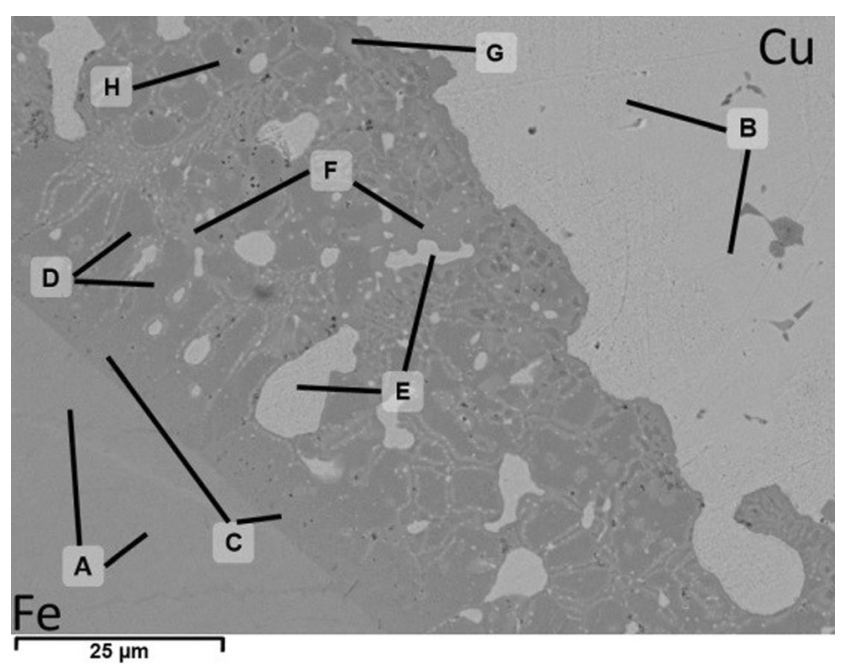

Fig. 10 Interface of stainless steel to $\mathrm{Cu}$ and IMC phase formation increasing the probability of the failure being located at this interface.

\subsection{SEM/EDS analysis}

To identify the nature of the possible IMC phases formed at these samples, the three previously identified areas were subjected to SEM/EDS analysis (Fig. 9).

The first layer to be analysed was the stainless steel- $\mathrm{Cu}$ interlayer. This layer is discontinuous in nature, and naturally, it results from the reaction between the stainless steel and the deposited $\mathrm{Cu}$ bead.

Figure 10 shows the stainless steel- $\mathrm{Cu}$ interface layer in greater detail and the places where the spectrums were collected (phases A-H). Inside the reaction layer, there are three distinguishable areas. These areas are identified by the following phases: phase $\mathrm{E}$ that has the lighter grey shade; phases $\mathrm{F}$ and $\mathrm{G}$ that have an intermediate shade of grey; and phases $\mathrm{C}, \mathrm{D}$ and $\mathrm{H}$ that have a darker shade.

In Table 3, the elemental composition in weight percentage is shown for the different phases indicated in Fig. 10.

As expected, phase A is stainless steel with a chemical composition very similar to the AISI 316L. Phase B is the $\mathrm{Cu}$ from the welding wire, but it is depleted from some of the silicon content expected ( $3 \% \mathrm{wt})$; this can be explained by the higher levels of Si present on the interface layer, and the $\mathrm{Si}$ has diffused to the stainless steel- $\mathrm{Cu}$ layer. Phases indicated by $\mathrm{C}$ and $\mathrm{D}$ and $\mathrm{H}$ have again a composition similar to the AISI $316 \mathrm{~L}$, with traces of silicon, $\mathrm{Cu}$ and Ti. The lighter phases present in the internal part of the layer represented by the phase E are mainly constituted by $\mathrm{Cu}$ with some $\mathrm{Fe}$ and $\mathrm{Ti}$ and can be considered as $\mathrm{Cu}$ that was segregated during the formation of the reaction layer; once again, it is observable a depletion of $\mathrm{Si}$ at these $\mathrm{Cu}$ islands. The phases within the interface layer with higher content of $\mathrm{Ti}$ are the phases represented by $\mathrm{F}$ and $\mathrm{G}$. Besides $\mathrm{Ti}$, these phases have also an increase in Si and Mo content; however, the main elements on these phases are $\mathrm{Fe}$ and $\mathrm{Cr}$. The amount of $\mathrm{Ti}$ in these phases increases with the distance from the stainless steel to the parent metal. Ti was segregated in the phases similar to $\mathrm{F}$ and $\mathrm{G}$ and is almost not present on the remainder phases in the stainless steel-Cu interface layer. This happened due to the non-equilibrium nature of the welding process, generating a concentration gradient of the $\mathrm{Ti}$ through the stainless steel- $\mathrm{Cu}$ interlayer that could be harmonised if the time-temperature cycles were longer. The Fe-Ti composition in these phases can justify the higher hardness present in the $\mathrm{Fe}-\mathrm{Cu}$ interlayer, due to the higher hardness shown by the Fe-Ti intermetallics.

The presence of $\mathrm{Ti}$ within this layer means that even with $\mathrm{CuSi}-3$ brazing wire with a lower melting point on a $1.7-\mathrm{mm}$ gap to restrict the melting of $\mathrm{Ti}$, it is not enough 
a

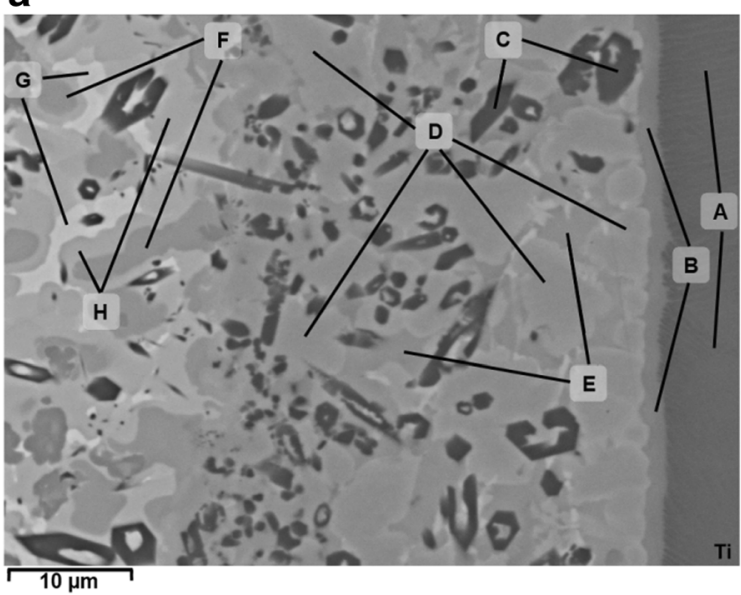

b

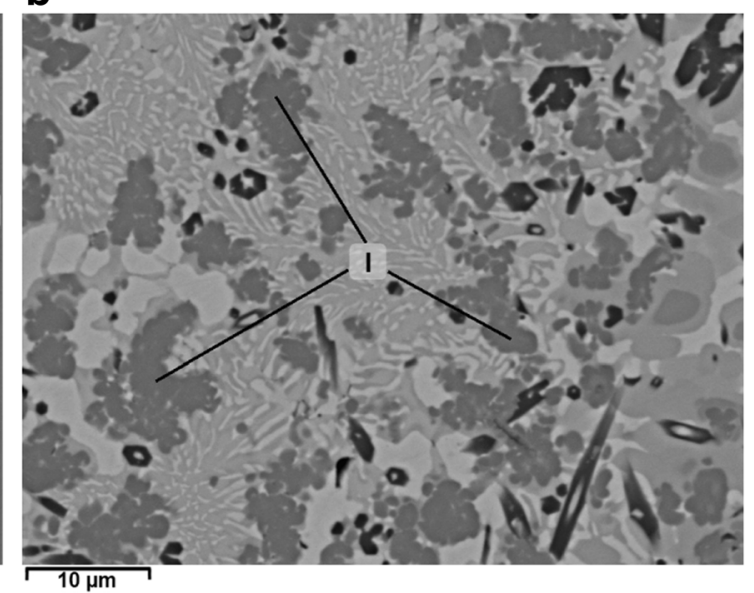

Fig. $11 \mathrm{Cu}-\mathrm{Ti}$ interface layer SEM backscattered image and phases investigated: a IMC layer close to the Ti parent metal and $\mathbf{b}$ transition between the IMC layer and the beginning of the $\mathrm{Cu}$ weld bead

to prevent $\mathrm{Ti}$ diffusion within the $\mathrm{Cu}$ weld bead. Ti diffuses across the deposited $\mathrm{CuSi}-3$ weld bead and interacts with $\mathrm{Fe}$ at the $\mathrm{Fe}-\mathrm{Cu}$ interface (the backscattered EDS images taken from the $\mathrm{Cu}-\mathrm{Ti}$ interface layer are shown in Fig. 11).

Each of the phases was identified by a letter, and multiple spectrums were analysed for each sample. The spectrum locations were identified by the lines shown in Fig. 11.

Phase A is the Ti base plate with the same distribution of Ti, $\mathrm{Al}$ and $\mathrm{V}$ as the parent material (Ti-6Al-4V).

Phase B is mainly composed of $\mathrm{Ti}(67.90 \%)$ and $\mathrm{Cu}$ (18.43\%). Phase B is a continuous layer between the base metal (Ti) and the main $\mathrm{Ti}-\mathrm{Cu}$ reaction layer. The identification of this layer can be done using the $\mathrm{Cu}-\mathrm{Ti}$ phase diagram due to the low values of $\mathrm{Si}, \mathrm{Fe}$ and $\mathrm{Cr}$ present. This IMC is a dual-phased IMC composed of $\mathrm{CuTi}_{2}$ and $\alpha$ Ti (Fig. 12a).

Phase $\mathrm{C}$ that appears in black on the SEM backscattered image is mainly composed of $\mathrm{Si}$ and $\mathrm{Ti}$, and the ratio between these elements is very close to $\mathrm{Ti}_{5} \mathrm{Si}_{3}$ phase on the Ti-Si (Fig. 12b) phase diagram. This phase has $20 \% \mathrm{wt}$ content while the $\mathrm{CuSi}-3$ wire only has $3 \%$; this shows once again that the silicon content of the wire was segregated to particular areas of the joint, producing IMC phases with higher contents of silicon.

Phases D and E compose almost all of the $\mathrm{Cu}-\mathrm{Ti}$ interface layer. Phase D has a cellular structure, and phase $\mathrm{E}$ has an intercellular space structure. These two phases are similar; however, from the $\mathrm{Fe}$ atomic
Cu-Ti

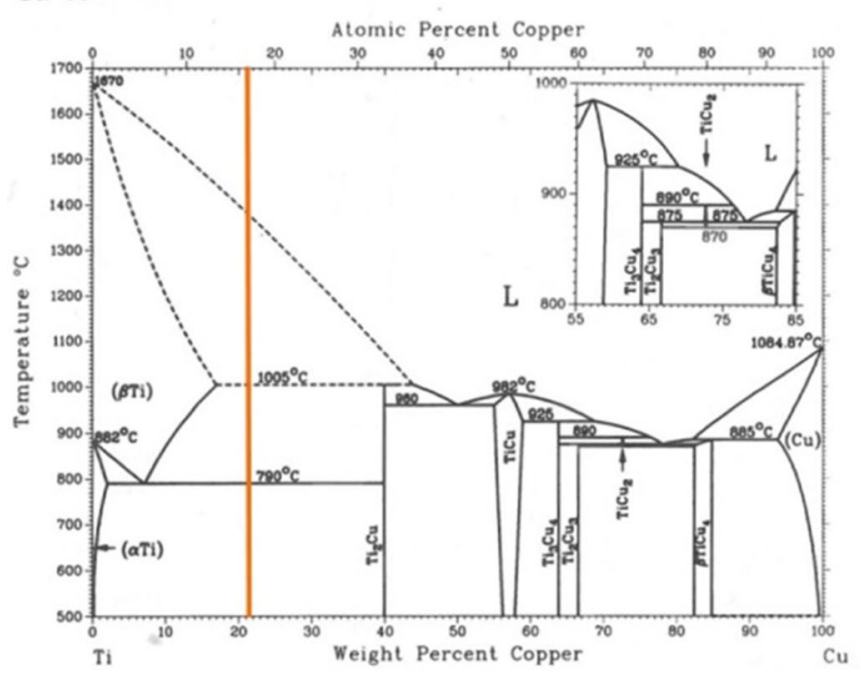

Si-Ti

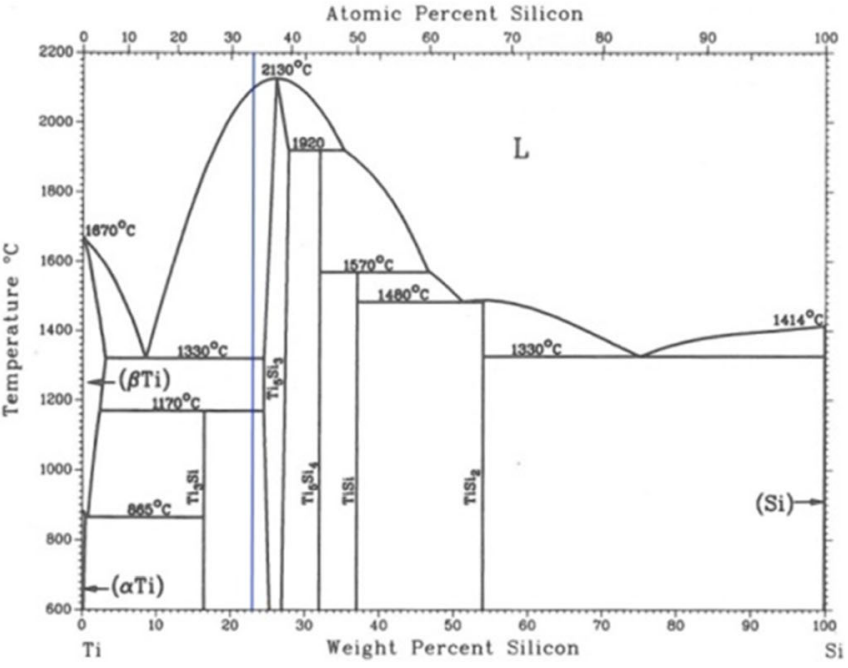

Fig. $12 \mathrm{Cu}$-Ti phase diagram with phase $\mathrm{B}$ indicated by an orange line: a $\mathrm{Si}$-Ti phase diagram with phase $\mathrm{C}$ represented by a blue line [1] 

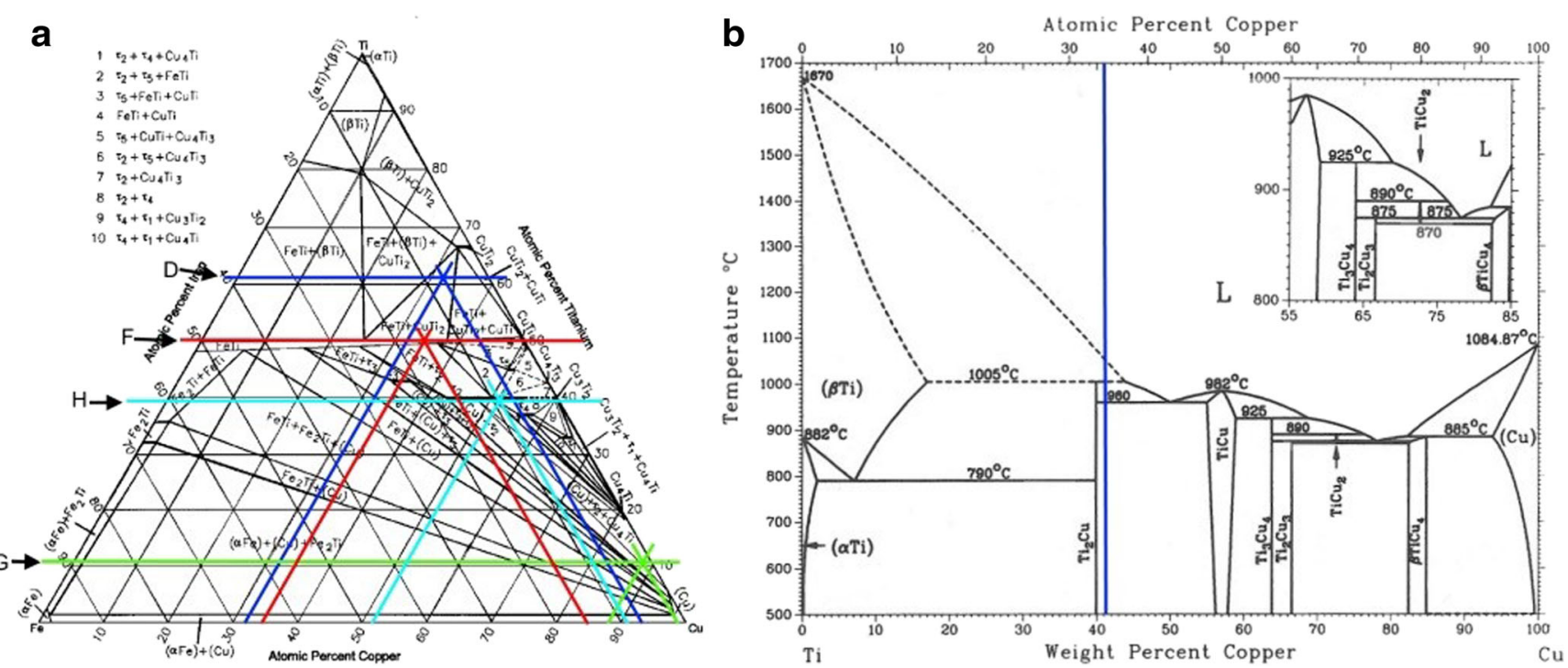

Fig. $13 \mathrm{Cu}-\mathrm{Fe}-\mathrm{Ti}$ phase diagram isothermal section at $849^{\circ} \mathrm{C}$ with phase $\mathrm{D}$ plotted (a) [14]. $\mathrm{Cu}-\mathrm{Ti}$ phase diagram with phase $\mathrm{E}$ plotted (b) [1]

proportion present, phase $\mathrm{D}$ can be estimated to the closest stoichiometric composition being a ternary IM compound, whilst phase E can be estimated to be a binary IMC. And so, phase D can be evaluated by a ternary $\mathrm{Cu}-\mathrm{Fe}-\mathrm{Ti}$ phase diagram [14] and phase E can be evaluated by a $\mathrm{Fe}-\mathrm{Cu}$ phase diagram (Fig. 12).

Phase D points to a binary phase compound of FeTi and $\mathrm{Ti}_{2} \mathrm{Cu}$, and phase $\mathrm{E}$ has a ratio between $\mathrm{Ti}$ and $\mathrm{Cu}$ very close to $\mathrm{Ti}_{2} \mathrm{Cu}$. F, G and $\mathrm{H}$ can be considered external to the $\mathrm{Cu}-\mathrm{Ti}$ reaction layer due to the higher discontinuity of these phases and the lower values of $\mathrm{Ti}$ when compared with the previous phases. Phases $\mathrm{F}$ and $\mathrm{H}$ are mainly composed of $\mathrm{Cu}, \mathrm{Ti}$ and $\mathrm{Fe}$, whilst phase $\mathrm{G}$ is only composed of $\mathrm{Cu}$ and Ti. These phases were also evaluated using the $\mathrm{Cu}-\mathrm{Fe}-\mathrm{Ti}$. When plotted on the $\mathrm{Cu}-\mathrm{Fe}-\mathrm{Ti}$ phase diagram, phase $\mathrm{F}$ is a dual-phased IMC

Table 4 Elemental composition in weight percentage from the phases identified on the $\mathrm{Cu}-\mathrm{Ti}$ interface layer

\begin{tabular}{llllllllll}
\hline & A & B & C & D & E & F & G & H & I \\
\hline $\mathrm{Al}$ & 5.83 & 4.97 & 0.26 & 3.54 & 2.68 & 1.35 & 1.35 & 0.86 & 0.12 \\
$\mathrm{Si}$ & - & 0.40 & 19.79 & 0.76 & 0.61 & 1.14 & - & 0.11 & 8.97 \\
$\mathrm{~S}$ & - & - & - & - & - & 0.09 & - & - & - \\
$\mathrm{Ti}$ & 90.07 & 67.90 & 66.62 & 49.43 & 56.92 & 41.43 & 8.21 & 31.93 & 33.01 \\
$\mathrm{~V}$ & 4.10 & 5.39 & 5.37 & 3.70 & - & - & - & - & 2.97 \\
$\mathrm{Cr}$ & - & - & 1.22 & 1.41 & - & 1.64 & - & 1.28 & 7.16 \\
$\mathrm{Mn}$ & - & - & - & 0.10 & - & - & 0.71 & 0.32 & 1.25 \\
$\mathrm{Fe}$ & - & 2.69 & 0.87 & 6.52 & - & 15.47 & 0.91 & 8.59 & 29.86 \\
$\mathrm{Ni}$ & - & 0.22 & - & 0.41 & - & 1.85 & - & 1.70 & 2.11 \\
$\mathrm{Cu}$ & - & 18.43 & 5.88 & 34.13 & 39.80 & 37.05 & 88.83 & 55.24 & 14.54 \\
\hline
\end{tabular}

composed of $\mathrm{FeTi}$ and $\mathrm{Ti}_{2} \mathrm{Cu}$, but much closer to $\mathrm{FeTi}$ composition than phase $\mathrm{D}$, showing a much bigger presence of $\mathrm{Fe}$, due to being out of the IMC layer and in the area with higher Fe concentrations shown in Fig. 13. Phase G points to a dual-phased $\tau_{2}$ and $\mathrm{TiCu}_{4}$ IMC phase in solid solution with $\mathrm{Cu}$, and finally, phase $\mathrm{H}$ indicates to be also a dual-phased IMC of $\tau_{2}+\tau_{4}\left(\mathrm{Ti}_{37} \mathrm{Cu}_{67-\mathrm{x}} \mathrm{Fe}_{\mathrm{x}}, x=5-7\right)$

After the $\mathrm{Cu}-\mathrm{Ti}$ interface layer and towards the $\mathrm{Cu}$ bead, another phase was observed at the backscattered EDS imaging (Fig. 11b). The main elements composing phase I (Fig. 10b) are $\mathrm{Ti}, \mathrm{Fe}, \mathrm{Cu}, \mathrm{Si}$ and $\mathrm{Cr}$, and their distribution is shown in Table 4. As this phase is manly composed of five components, it was impossible to identify it against a dual or ternary phase diagram.

The final area to be investigated was the area of dispersed IMC phases within the $\mathrm{Cu}$ bead. Two different areas inside the $\mathrm{Cu}$ bead were analysed. One was closer to the stainless steel and other close to the Ti. These two different areas were analysed to verify if the proximity to the different parent metals has an influence on the IMC formation and composition. Figure 14 shows the two different IMC areas and the corresponding phases selected.

The correspondent elemental distribution in weight percent is shown in Table 5. The IMCs identified are mainly composed of $\mathrm{Fe}, \mathrm{Cr}, \mathrm{Si}, \mathrm{Ti}$ and $\mathrm{Cu}$. The correct identification of the stoichiometric composition of the IMC phases was not possible, due to the multiplicity of important elements present within these phases.

Due to the high cooling rate, it is possible to observe coring on the IMC formed closer to the stainless steel, with the presence of different elemental concentration values in the same 
a

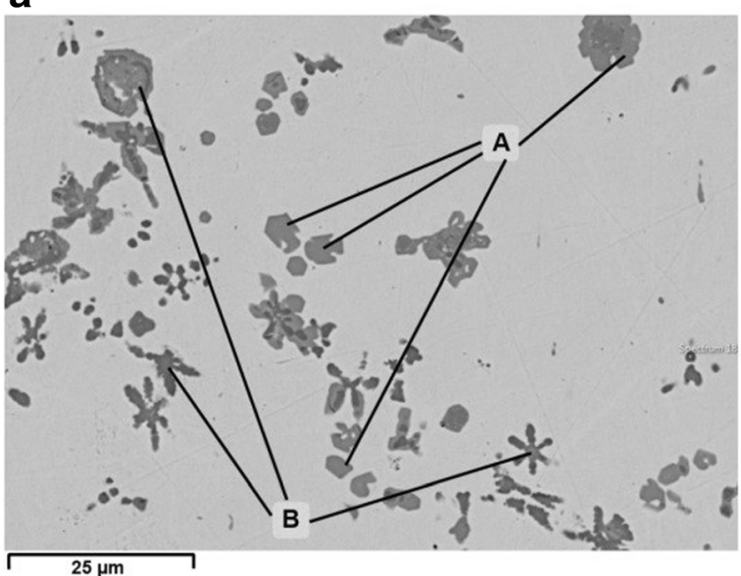

b

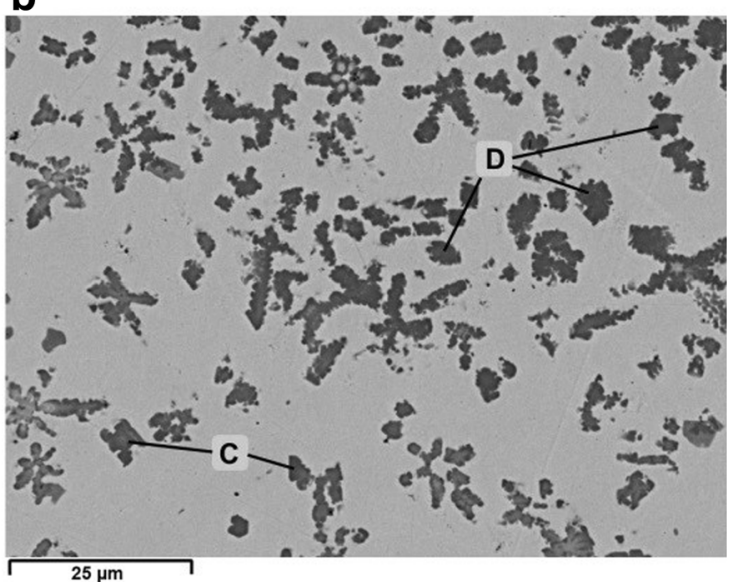

Fig. 14 Scattered IMCs close to stainless steel SEM backscattered image and phases investigated (a) and scattered IMC phases close to Ti (b)

intermetallic phase. This reveals the non-equilibrium conditions experienced during the welding process. The morphology of the IMC phases is also different with the phases closer to Ti being more angular in shape while the phases closer to the stainless steel are more circular or spherical.

Phases C and D IMC phases have higher levels of Ti when compared with the IMCs close to the stainless steel (phases A and B), showing that the IMC composition changes with the distance to the parent metals. This also reveals a gradient of $\mathrm{Ti}$ and stainless steel present inside the $\mathrm{Cu}$ bead.

\subsection{Mechanical strength}

To evaluate the success of using $\mathrm{Cu}$ as a transition metal between $\mathrm{Ti}$ and stainless steel, mechanical tests were also carried out and the results are shown in Fig. 15.

The ultimate tensile strength of each sample was calculated using the thickest value for the cross-sectional area of each sample and the maximum thickness of the

Table 5 Elemental composition in weight percentage from the phases identified in Fig. 14

\begin{tabular}{lrrrrrrrr}
\hline & \multicolumn{1}{l}{$\mathrm{Si}$} & \multicolumn{1}{l}{$\mathrm{Ti}$} & $\mathrm{V}$ & \multicolumn{1}{l}{$\mathrm{Cr}$} & \multicolumn{1}{l}{$\mathrm{Fe}$} & $\mathrm{Ni}$ & $\mathrm{Cu}$ & $\mathrm{Mo}$ \\
\hline $\mathrm{A}$ & 10.34 & 6.48 & 0.00 & 17.19 & 56.03 & 3.56 & 6.42 & 0.00 \\
$\mathrm{~B}$ & 11.27 & 16.54 & 1.19 & 8.87 & 43.91 & 2.70 & 9.87 & 5.65 \\
$\mathrm{C}$ & 11.85 & 27.95 & 1.43 & 7.04 & 39.56 & 3.49 & 8.24 & 0.44 \\
$\mathrm{D}$ & 11.50 & 21.04 & 0.55 & 8.92 & 46.86 & 3.09 & 6.89 & 1.17 \\
\hline
\end{tabular}

The IMCs identified are mainly composed of $\mathrm{Fe}, \mathrm{Cr}$, $\mathrm{Si}$, Ti and $\mathrm{Cu}$. The correct identification of the stoichiometric composition of the IMC phases was not possible, due to the multiplicity of important elements present within these phases sample; this includes the reinforcement and root penetration curves introduced by the $\mathrm{CuSi}-3$ brazed metal. This way, a conservative calculation of the tensile load for each sample was achieved.

The welded samples show an increase of tensile strength with the increase of the heat input. However, the welding wire positioning does not seem to be a controlling parameter of this welding process. This characteristic denotes that the welding process is tolerant to the positioning of the wire in relation to the parent metals. This will facilitate the alignment of the welding process making the welding technique more relevant to industry application.

The samples with higher tensile load also have the maximum strain with the maximum present on the sample CMT 4 with a strain close to $2 \%$. The mechanical test results show a clear increase not only on tensile strength but also in ductility of these specimens, with the heat input. This indicates that this process can be further improved, by a further increase. As the IMC formation is time-temperature dependant, there is critical value where an increase in heat input and, consequently, an increase in the time-temperature cycle will have a negative effect in the tensile strength of the joint. However, this point was not achieved during this work. From that value of heat input, a further increase of energy will always result in a loss of mechanical properties of the welded joint.

The tensile test results can be compared with studies done in infrared brazing of Ti and stainless steel using $\mathrm{Cu}$ as an interlayer [11] and the study done using electron beam welding to join the same parent metals using $\mathrm{Cu}$ as an interlayer [9]. The mechanical properties reported by this study are a maximum tensile strength of $318 \mathrm{MPa}$ with a ductility of $8.5 \%$ and $234 \mathrm{MPa}$ with a 
a

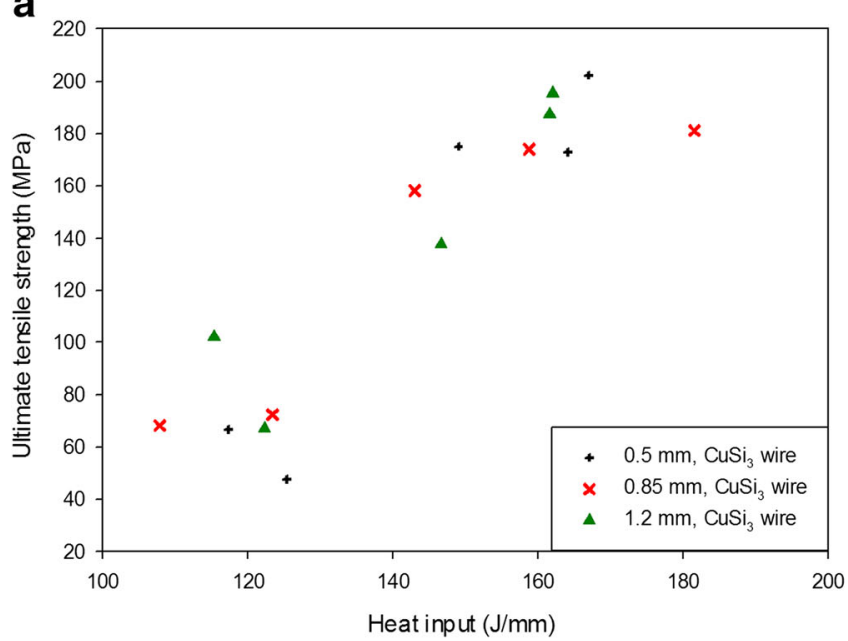

b

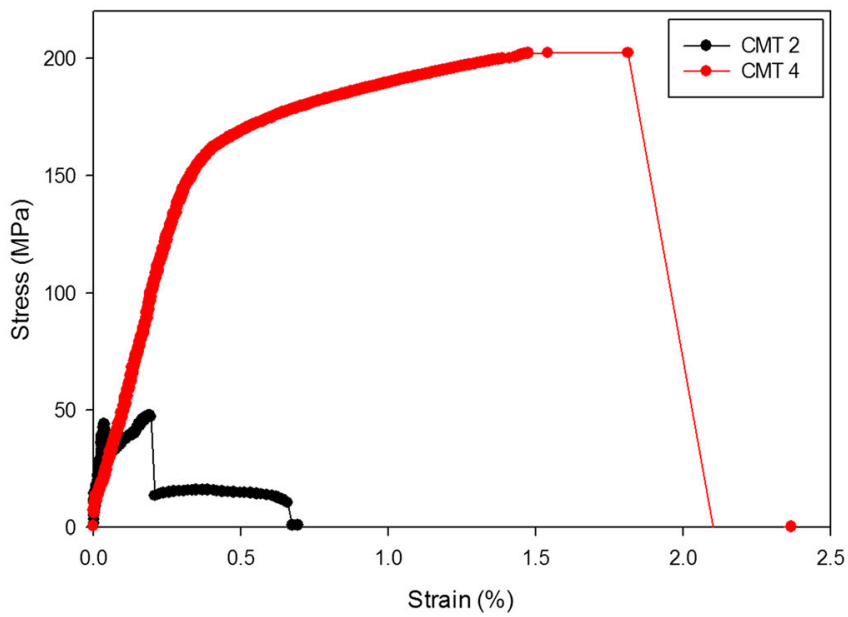

Fig. 15 Ultimate tensile strength vs heat input for all welded samples (a) and stress strain curves for samples CMT 2 and 4 (b)

$3.6 \%$ elongation, respectively. These results exceed mechanical strength of the results presented in this work; however, the added flexibility of this joining process when compared with infrared brazing and electron beam welding can result on easier and cost-effective application in industry.

\section{Conclusions}

It was possible to join stainless steel and $\mathrm{Ti}$ using $\mathrm{CuSi}-3$ welding wire.

The heat input revealed to be the dominant parameter during the study developed. The maximum tensile properties were obtained for the samples brazed with higher heat input. Samples with the lowest heat input did not wet properly the parent metals, resulting in the lowest mechanical properties.

The IM phase formation was not avoided, but the IMCs formed are more ductile in nature when compared with the $\mathrm{Fe}-\mathrm{Ti}$ IMCs. The phases identified are and the maximum hardness measured was of $1000 \mathrm{HV} 0.1$.

The IMC phases identified are mainly located at the interfaces between the parent metals and the $\mathrm{Cu}$. However, scattered IMC phases are present at the $\mathrm{Cu}$ bead.

Acknowledgments Supriyo Ganguly acknowledges the support received vide EPSRC (Engineering and Physical Sciences Research Council) project no. EP/J017086/1. Enquiries for access to the data referred to this article should be directed to researchdata@cranfield.ac.uk.

Open Access This article is distributed under the terms of the Creative Commons Attribution 4.0 International License (http:// creativecommons.org/licenses/by/4.0/), which permits unrestricted use, distribution, and reproduction in any medium, provided you give appropriate credit to the original author(s) and the source, provide a link to the Creative Commons license, and indicate if changes were made.

\section{References}

1. ASM International (1992) ASM handbook: alloy phase diagrams v. 3. ASM International

2. Poddar D (2009) Solid-state diffusion bonding of commercially pure titanium and precipitation hardening stainless steel. Int $\mathbf{J}$ Recent Trends Eng 1:93-99

3. Kundu S, Chatterjee S (2008) Diffusion bonding between commercially pure titanium and micro-duplex stainless steel. Mater Sci Eng A 480:316-322. doi:10.1016/j.msea.2007.07. 033

4. Fazel-Najafabadi M, Kashani-Bozorg SF, Zarei-Hanzaki a (2011) Dissimilar lap joining of 304 stainless steel to CP-Ti employing friction stir welding. Mater Des 32:1824-1832. doi:10.1016/j. matdes.2010.12.026

5. Kahraman N, Gulenc B, Findik F (2005) Joining of titanium/ stainless steel by explosive welding and effect on interface. $\mathrm{J}$ Mater Process Technol 169:127-133. doi:10.1016/j.jmatprotec. 2005.06.045

6. Shanmugarajan B, Padmanabham G (2012) Fusion welding studies using laser on Ti-SS dissimilar combination. Opt Lasers Eng 50: 1621-1627. doi:10.1016/j.optlaseng.2012.05.008

7. Lee JG, Hong SJ, Lee MK, Rhee CK (2009) High strength bonding of titanium to stainless steel using an Ag interlayer. J Nucl Mater 395:145-149. doi:10.1016/j.jnucmat.2009.10.045

8. Shiue RK, Wu SK, Chan CH, Huang CS (2006) Infrared brazing of Ti-6Al-4V and 17-4 $\mathrm{PH}$ stainless steel with a nickel barrier layer. Metall Mater Trans A 37:2207-2217. doi:10.1007/BF02586140

9. Wang T, Zhang B, Chen G et al (2010) Electron beam welding of Ti-15-3 titanium alloy to 304 stainless steel with copper interlayer sheet. Trans Nonferrous Met Soc China 20:1829-1834. doi:10. 1016/S1003-6326(09)60381-2

10. Tomashchuk I, Sallamand P, Andrzejewski H, Grevey D (2011) The formation of intermetallics in dissimilar Ti6A14V/copper/ 
AISI $316 \mathrm{~L}$ electron beam and Nd:YAG laser joints. Intermetallics 19:1466-1473. doi:10.1016/j.intermet.2011.05.016

11. Kundu S, Ghosh M, Laik a et al (2005) Diffusion bonding of commercially pure titanium to 304 stainless steel using copper interlayer. Mater Sci Eng A 407:154-160. doi:10.1016/j.msea.2005.07.010

12. BS EN ISO 6507-1 (2005) Metallic materials-Vickers hardness test - part 1: test method. Br Stand 20
13. Pépe N, Egerland S, Colegrove P a et al (2011) Measuring the process efficiency of controlled gas metal arc welding processes. Sci Technol Weld Join 16:412-417. doi:10.1179/1362171810Y. 0000000029

14. Raghavan V (2002) Cu-Fe-Ti (copper-iron-titanium). J Phase Equilibria 23:172-174. doi:10.1361/1054971023604152 